\title{
Individual Differences in Emotional Contagion of Salespersons: Its Effect on Performance and Burnout
}

\author{
Willem Verbeke \\ Erasmus University, Rotterdam
}

\begin{abstract}
This article explores the emotional contagion hypothesis, proposed by Hatfield, Cacioppo, and Rapson (1994), in a sales context. Specifically, the emotional contagion hypothesis explains how the emotions of two people (e.g., salesperson and customer) during a conversation are transmitted from one to the other via facial cues, and that these emotions affect the outcome of that interaction. The emotional contagion hypothesis implies that there are definitive individual differences concerning whether someone is either sensitive to emotions from others or able to transmit his or her emotions onto others. This study explores whether these individual differences are assets or liabilities over the long term for salespersons in a sales organization. The data in this study show that a salesperson's ability to infect others with his or her emotions is an asset (because it can lead to higher performance). In addition, being sensitive to the emotions of others is an asset (it can also lead to better performance); at the same time it is a liability (because of the higher risk of burnout). This study further explores how emotionally sensitive salespersons develop burnout as a consequence of role stress, which then affects their performance. (01997 John Wiley \& Sons, Inc.
\end{abstract}

"He'd come down, but it would always come back. It was force. That's what selling was. He didn't have to be smart. But he had to have that 
quality, that emotion. He had it . . . When it was operating this force conveyed a feeling of euphoria and power. He judged everything he did by how much it moved the needle of his emotions - and other people's emotions - toward this same feeling." (Dorsey, 1994, pp. 20-21)

Because salespersons operate as boundary spanners in organizations, it is not surprising that sales specialists have been studying the social interactions of salespersons inside and outside the organization. Their interactions with internal role members (Behrman \& Perreault, 1982) and with external role members (Weitz, 1981) have attracted much attention. The way salespersons interact with their role members has been a key factor in predicting variables like sales performance, satisfaction, turnover intentions (Churchill, Ford, Hartley, \& Walker, 1985). Most of the work today on salesperson-role member interactions, especially with customers, has been done from a cognitive point of view (Weitz, 1981). Emotions have received much less attention, even though we know that they can substantially affect the interactions between people and their role members. Because perhaps 50\% of the information that is transmitted during a conversation is nonverbal, and because nonverbal communication is largely affected by emotions, more emphasis is needed on the following questions:

1. How are emotions and non-verbal cues related?

2. How do these nonverbal cues and emotions affect the dynamics of a conversation?

Recently, the emotional contagion hypothesis suggested by Hatfield, Cacioppo, and Rapson (1994) has sought to explain how two people's emotions, transmitted through nonverbal cues, affect the dynamics of conversation. The emotional contagion hypothesis specifically suggests that some psychophysiological processes cause facial reactions. These facial reactions can transmit the emotions of a person to other people. The emotional contagion hypothesis also includes a theory on individual differences, concerning the ability of a person either to infect another person with their emotions, or to become infected by another person's emotions (Hatfield et al., 1994). Those people who are able to infect others with their emotions and become infected by their emotions could be perceived as emotionally intelligent people (Goleman, 1995). These emotionally intelligent people might be at an advantage in society and daily life. But is this emotional intelligence also a blessing within organizations, especially for people working in boundary spanning positions? This question will be dealt with here.

This article explores in more depth how the emotional contagion hypothesis might help us to understand how the emotions of a salesperson affect the interactions with the members of the role set. Particularly long-term consequences - burnout and performance - for salespersons 
who are able to infect the role members and/or who become infected by role members are studied. First, the need for emotions in the area of personal selling is briefly explained and then this article proceeds via a thorough discussion of the emotional contagion hypothesis. In addition, hypotheses dealing with long-term consequences of being able to infect the emotions of another person or to be infected by another person's emotions are proposed. Further, it is explained how burnout within salespersons who are sensitive to emotions of another person arises as a consequence of role stress and affects the performance of this salesperson. Methods are explained, and results are analyzed and discussed. Managerial implications are presented.

\section{Need for the Study of Emotions During Salesperson-Role Member Interaction}

The study of sales interactions - the exchange of relationships between salespersons and role members, especially customers, has attained an important place in the field of marketing (Szymansky \& Churchill, 1990; Weitz, 1981; Weitz, Sujan, \& Sujan, 1986). The work of Weitz (1981) in particular relates to a framework of sales interaction that is likely to yield interesting and potentially meaningful insights into the performance of salespersons. Although there are important differences among the various frameworks of sales interaction (e.g., Leigh \& Rhetans, 1984; Schuster \& Danes, 1986; Weitz, et al., 1986) most of them are rooted in cognitive psychology. Sales interactions are viewed from an information-processing perspective exemplified by the salesman-as-computer analogy: The altering of sales behaviors during or across customer interactions is based on perceived informationrepresented as declarative knowledge - about the nature of the selling situation (Weitz et al., 1986). According to this paradigm, salespersons should be trained to develop consciously a declarative knowledge base and from there develop behaviors (procedural knowledge) that fit the profile of the customer. There is a substantial interest in this stream of research, which has provided us with interesting results, and also with widely used training methods for salespersons.

Many scholars in sales and sales management have suggested that emotions affect the dynamics of a conversation between a salesperson and his role members, specifically with his customers. In the literature on personal selling and sales management of the role of touching (Hornik, 1992), the usage of relational verbal messages (Soldow \& Thomas, 1984) as well as the effect of the environment in which a customer-client interaction takes place (Bitner, 1992) are mentioned. But beyond this attention to emotions, research in this area has been sparse. This gap in the research is somewhat curious, because practitioners frequently suggest that: "the first two minutes a salesperson spends with a prospect can be very important. Making a favorable first 
impression usually produces a prospect willing to listen. A negative first impression, on the other hand, sets up a barrier that may never be hurdled" (Weitz, Castlebery, \& Tanner, 1992, p. 223). Verbal cues, and especially nonverbal cues from the part of the sender, which set the emotional tone in a conversation, make up for this process of impression (Weitz et al, 1993). There is new evidence that in this impression management implicit ${ }^{1}$ cognitive and emotional processes of the part of the receiver are taking place. These emotional impression processes are intuitively recognizable for many (sales) people, yet they remain elusive for scientists. Psychologists, in frameworks such as Zajonc's (1965) social facilitation theory, have already hinted that the presence of others (customers) enhances behaviors and performances (salespersons). Once a person (Salesperson) contacts another person (customer), the person becomes aroused by this other person. It is not counterintuitive to suggest that this process of arousal also takes place in the opposite direction. Cacioppo recently suggested that "just seeing someone express an emotion can evoke that mood, whether you realize you mimic the facial expression or not" (Goleman, 1995, p. 116). Both Zajonc and Cacioppo point to the unconscious manner in which people become influenced. These unconscious but elusive pathways have recently attracted the attention of many researchers (Schacter \& Tulving, 1994). It is in this context that the emotional contagion hypothesis should be situated, and this is the topic in this article.

\section{The Emotional Contagion Hypothesis}

To explain how emotions are transmitted between people, the emotional contagion hypothesis focuses primarily on two main components. First, it suggests that some processes are responsible for emotional contagion, and second, it suggests that there are strong individual differences in the way that some people are susceptible to emotional contagion or are able to transmit their emotions to others.

Processes in Emotional Contagion. The following statements about the emotional contagion processes are proposed:

1. In interactions, people automatically and continuously tend to mimic and synchronize their movements with the facial expressions, voices, postures movements, and the instrumental behaviors of others. This process is called primitive emotional contagion, but in the emotional contagion hypothesis the facial expressions in particular are targeted.

\footnotetext{
${ }^{1}$ The implicit cognitive processes reflect the way in which "traces of past experience affect some performance, even though the influential earlier experience is not remembered in the usual sense - that is, it is unavailable to self-report or introspection" (Schacter \& Tulving, 1994) (see Greenwald \& Banaji, 1995).
} 
2. Subjective emotional experiences are affected, moment to moment, by the activation of feedback from such facial mimicry. This point of view reflects the thesis that emotion-related movement in the face is controlled by an innate circuitry. This innate circuitry affects physiological loops in the body that give rise to specific emotions (Tassinary, Cacioppo, \& Geen, 1992) as well as cognitions (Damasio, 1994).

3. As a consequence of Propositions 1 and 2, people tend to catch others' emotions, moment to moment.

Individual Differences. The second part of the emotional contagion hypothesis is that if people mimic and synchronize reactions with one another, then some people might be powerful transmitters of emotions (they are able to infect others with their emotions) and others might be powerful catchers of emotions (they assume the senders' emotions). The basis for this distinction lies in the individual response stereotype, which refers to variance in somatic and physiological activity to person-situation interactions.

Transmitters, those who by their innate bodily circuitry transmit their emotions to others, "were charismatic, colorful, and entertaining; had often taught, lectured, or worked as a salesperson .... (they) scored high on dominance, affiliation, and exhibition" (Hatfield et al., 1994, p. 138). This ability to transmit emotion can be gauged by the facial expressiveness scale (Klein \& Cacioppo, 1993). In many cases, being able to transmit positive emotions to another person might cause this other person to become more accessible to the intention of the conversation (Isen \& Means, 1983). It must be emphasized that the controlling ability of the transmitters does not appear to be a conscious process; rather, it is an automatic and implicit one. We therefore call the ability to control primitive control.

Infection-prone people (those susceptible to the emotions of others) are people whose attention tends to be riveted to others. Therefore, they are more likely to be affected by other people's emotions. The result of this ability is that rapport building with others may come more easily. Because of this, the susceptible people are more likely to make the person with whom they communicate (e.g., the customer) feel relaxed, so that the latter is willing to share more information. The infection-prone person and his or her interlocutor then share a common frame of reference during conversations (Sperber \& Wilson, 1987). There is, however, a flip side to this. These infection-prone people make themselves miserable, because they can be affected by the negative emotions of others - who are eager to share their information with empathic people-and because more people, especially those with negative feelings, may want to open up to them. Like the controlling ability, the attentional involvement toward others appears to be an unconscious and automatic process. 


\section{The Configuration}

Hatfield et al. (1994) suggested that, although in theory some people are catchers of emotions and others transmitters of emotions, these categories are not mutually exclusive. Using scales to gauge people's ability to transmit or catch emotions, Klein and Cacioppo (1993) found that the categories were not orthogonal. It is therefore more realistic to take a configurational approach to this problem: Some catchers might be transmitters and vice versa. Although not explicitly stated by Hatfield et al. (1994) it is possible to develop a fourfold typology, as shown in Table 1.

The first group of people are called the charismatics: They are able to infect others with their emotions and also to become infected by the emotions of others. The second group, called the empathetics, are people who are susceptible to emotions, but who are not able to infect others with their emotions. The third group, called the expansives, are able to infect others, but they do so without any form of empathy. For example, during social situations, they might display ill-fitting or insensitive behaviors (jokes at a funeral). The last groups are called the blands. These people are neither able to infect nor to be infected (the people you never remember having seen at a party).

\section{Transmitting and/or Catching Emotions: Assets or Liabilities?}

Now that the emotional contagion and the individual differences are explained on whether one infects or is infected by another's emotions, the implications for salespersons who work in boundary positions can be explained. It seems that sales managers would be especially interested in hiring emotionally intelligent salespersons, especially charismatic salespersons. The charismatics are assets for the organizations because, one might expect, they will perform better, as they are able to empathize with the customer (and the other members of the role set) and also to control the customer (and other members of the role set) implicitly. However, there is another side to the story. Salespersons who become in-

Table 1. The Typology of People Based upon Their Emotional Constitution

\begin{tabular}{lcc}
\hline & $\begin{array}{c}\text { High Ability to Infect } \\
\text { (High Primitive Control) }\end{array}$ & $\begin{array}{c}\text { Low Ability to Infect } \\
\text { (Low Primitive Control) }\end{array}$ \\
\hline $\begin{array}{l}\text { High Capability To Be } \\
\text { Infected } \\
\text { (High Primitive Empathy) }\end{array}$ & Charismatics (CH) & Empathetics (EM) \\
$\begin{array}{l}\text { Low Capability To Be } \\
\text { Infected } \\
\text { (Low Primitive Empathy) }\end{array}$ & Expansives (EX) & Bland (BL) \\
\hline
\end{tabular}


fected by others might become overwhelmed by the negative feelings or complaints of their customers. In the course of time these negative consequences can be very costly to a salesperson and might cause burnout (Lee \& Ashfort, 1996). This burnout occurs because if situations imply negative consequences for a person, these negative consequences will be elaborated more intensely than commensurable positive consequences and so will deplete a person's resources (Kahneman \& Tversky, 1985). Thus, although emotional sensitivity can be an asset on the one hand, it can become a liability on the other hand. In what follows these observations are further elaborated and specifically targeted to the configuration introduced in Table 1.

\section{Assets: Consequences for Sales Performance.}

Sales success, which includes obtaining sales volume, being able to build a rapport with customers, and having relationship proficiency with customers, has been attributed to the ability to control the customer and to empathize with him or her (McBane, 1995; Olshavsky, 1983; Spiro \& Weitz, 1990; Willet \& Pennington, 1966). Both abilities, being able to control and being able to empathize, are therefore perceived as assets.

The charismatics - the salespersons who have a high score on primitive empathy and primitive control-will be the most successful within the organization. Their ability to elicit information and at the same time to control the conversation allows them to be relevant to the customer (Sperber \& Wilson, 1987). Specifically, they will have the highest score in sales volume, sales interaction, and relationship building. All other groups will score lower on these performance dimensions. However, we expect gradations. First, the empathetics (who are only primitively emphatic) might score second as their ability to build up a rapport with customers will most likely elicit information from the customer, thus allowing them to be better attuned to the customer. This hypothesis is in line with recent work on customer orientation and marketing orientation, which expects that the salesperson remains attuned to the customer's needs and desires (Saxe \& Weitz, 1986). The expansives (those who can control but lack empathy) will score third: Research has shown that ability to control is an important asset (Olshavsky, 1973; Spiro \& Weitz, 1990; Willet \& Pennington, 1966). The blands will score lowest, as they are weak in rapport building and show lack of control. These weaknesses do not allow blands either to create relevance or to direct the conversation.

H1: On performance, the charismatic salespeople will score higher than the empathetics, followed by the expansives and the blands on all three sales performance dimensions.

Liability: Proneness to Burnout. Burnout has substantial costs for the organization, as it increases turnover and reduces productivity 
(Cordes \& Dougherty, 1993) and therefore, it is becoming a salient factor to which managers give attention. Burnout reflects how poorly a person is coping in the long term with additional (role) stress, thus reflecting both the amount of (role) stress that can be handled and the effectiveness of the coping styles. In other terms, although the (role) stress level in an organization might be the same to several salespersons, burnout will develop by those who are unable to handle the stress (Singh, Goolsby, \& Rhoads, 1994). Three burnout dimensions, as suggested by Maslach and Jackson (1981), are considered in this study: (a) emotional exhaustion (i.e., "a lack of energy and a feeling that one's emotional resources are used up" (Cordes \& Dougherty, 1993 , p. 623), (b) depersonalization (i.e., the salesperson has a tendency to think of others - like customers and colleagues - as objects to be used instrumentally), and (c) reduced personal accomplishment (i.e., "a person's tendency to evaluate oneself negatively") (Cordes \& Dougherty, 1993, p. 623).

From what was just explained, it can be concluded that salespeople who are empathic might just be prone to burnout, because they put more effort into understanding members of the role set, and because they are implicitly unable to control others, they are unable to compensate for this investment. The charismatics will also be at risk for burnout, but their ability to control the customer and other members of the role set as well might compensate this risk. Therefore, the charismatics will rank second in the risk for burnout. Next are the expansives. Their weak adaptive abilities (inability to attune to other persons) make them vulnerable in the long term as well. The blands will have the lowest likelihood of burnout because they are not driven to fulfill expectations of others.

H2: Empathetics (more than the charismatics) the expansives, and then the blands will experience more burnout on all three dimensions of burnout

An Exploratory Analysis of the Amplifying Role of Sensitivity to
Emotions on the Mediating Role of Burnout. Thus far we have
been explaining that being a catcher (or being contagious to the emo-
tions of others) is not only an asset, but also a liability. It is suggested
that the salespersons who are sensitive to the emotions of others
might put themselves at risk, because they might tune too much into
the negative emotions of others. However, it would be of interest to un-
derstand exactly how this burnout process emerges and how it affects
the performance of a salesperson. Recently, within the field of market-
ing, an attempt has been made by Singh et al. (1994) to explain how
burnout, as a consequence of role stress, affects the performance of a
salesperson (which is called the mediating role of burnout in the stress
process). Their model reflects an important insight into why burnout is 
becoming an important component in stress research: Role stress usually has a moderate and a significant effect on performance (around -0.25 on average). However, if this effect was only that small, it would not be worth paying much attention to. When researchers encounter such cases - a low correlation between two variables that is intuitively not evident - they will introduce in their model a mediator between these two variables (Baron \& Kenny, 1986). In this context, Singh et al. (1994) introduce burnout as a mediator between role stress and performance. They observed a strong path between role stress and burnout as well as between burnout and performance. These strong paths reflect the fact that when people are unable to handle the role stress, they develop burnout, and as a consequence they have lower performance. Because burnout, as opposed to role stress, is largely a reflection of how a person copes with stress, one might expect large effects of some individual differences on burnout, especially for those who are sensitive to another person's emotions (the catchers). So when the sensitive salespeople encounter role stress, they might develop burnout in the course of time (the path role stress and burnout will become more substantial), and burnout will consequently affect their performance (the path from burnout to performance will be more substantial). These paths will be less substantial for salespersons who are not sensitive to the emotions of others. Therefore, the following hypothesis is presented:

H3: Burnout will function as a stronger mediator for the catchers (emphatic and charismatics), and this mediating role of burnout will be substantially reduced for the transmitters (expansives and the blands).

\section{METHOD}

In order to test the hypotheses concerning the emotional contagion hypothesis industrial salespersons were chosen. First, the sampling will be discussed, followed by the psychometric properties of the scales.

\section{Sampling}

In order to obtain data for this study we approached organizations (representing a cross section of business to business organizations) by telephone with a scripted interview, and asked sales managers whether they were interested in participating in this study. Dun's $25.000^{2}$ was used to acquire the names and telephone numbers of the companies. If the sales manager was interested, a letter was sent in which the study, the time frame, and the conditions for both parties

${ }^{2}$ Dun \& Bradstreet International B.V. (1994). Dun's 25.000. 
were explained in more detail. ${ }^{3}$ During the next telephone call the final decision on participating in the study was made, and the procedures were explained. All questionnaires were forwarded in one package to the sales manager, who was responsible for distributing the questionnaires. Every salesperson got one questionnaire, a cover letter promising confidentiality, a support letter from the management, a return envelope addressed to the experimenter, and a lottery note with a chance of winning a compact disk (20 CDs in total). A total of 89 companies, ranging from small to medium in size, were approached by phone; 64 were sent a letter. In the end 27 companies decided to participate. The amount of salespersons ranged from 2 to 52, equally divided among the participating companies.

All participating companies were drawn from the manufacturing, services, and wholesaling sectors, and represent a cross section of these sectors in the Netherlands (wholesaling 30\%, services 50\%, and industry 20\%). In total 324 questionnaires were sent. One month after the questionnaires were sent to the participating organizations the sales managers were contacted and asked to bring the study to the attention of their salespersons once more. Within eight weeks 201 questionnaires were returned. Three questionnaires had not been filled in properly, and thus could not be used. The net response was $61.1 \%$.

Demographically the population used in the study can be described as follows: $96 \%$ male and $4 \%$ female. The amount of sales experience varied from 1 to 40 years, with an average of 12.5 years. The average age was 37 years. On average the salespersons spend $66 \%$ of their time with their clients. Their salary varied from $f 50,000$ to $f 140,000$ ( $f 1.65=1 \$$ ) with an average of $f 70,000$. The average additional bonus or commission was $14.9 \%$.

\section{Scales}

Although sales performance implies many dimensions (Berhman \& Perreault, 1982, used five dimensions), this study only focuses on three measures: the ability to obtain sales volume (meaning to gain the sales targets), the ability to interact with customers, and the ability to engage in relationships with customers. The sales volume scales and the sales presentations scales were adopted from Berhman and Perreault (1982). In order to estimate the performance on relationship capacity a new dimension was added. This scale was adopted from Swenson, Singh, and Rhoads (1994). In all three cases the salespersons were asked to evaluate themselves. Based upon their meta-analysis, Churchill et al. (1985) have noted that such self-rating performance

\footnotetext{
${ }^{3}$ First, all salespeople should participate in order to avoid bias by the sales manager in the selection. Second, the questionnaires should be returned within 8 weeks. Third, management had to show their support to the study and promise confidentiality. This was partly done via a support letter that was sent with the questionnaire.
} 
Table 2. The Reliabilities of the Scales Used in the Studies

\begin{tabular}{lccc}
\hline Dimensions & Items & Mean $(1-7)$ & $\alpha$ \\
\hline Emotional exhaustion (EE) & 8 & 2.55 & 0.80 \\
Depersonalization (DE) & 8 & 2.97 & 0.75 \\
Reduced personal accomplishment (RPA) & 8 & 2.58 & 0.80 \\
Sales volume (SO) & 7 & 4.86 & 0.90 \\
Sales presentations (SP) & 6 & 5.15 & 0.86 \\
Relationship capacity (RC) & 11 & 5.42 & 0.93 \\
Emotional contagion (EC) & $13^{*}$ & 3.77 & 0.70 \\
Facial expressiveness (FE) & 10 & 3.58 & 0.83 \\
Role conflict (RC) & 4 & 3.28 & 0.76 \\
Role overload (RO) & 4 & 4.02 & 0.72 \\
Role ambiguity (RA) & 4 & 2.59 & 0.72 \\
\hline
\end{tabular}

*Originally the emotional contagion scale contained 18 questions. We used a reduced version of this scale by removing the reversed questions.

measures are not necessarily biased. Likewise, Heneman (1974) has reported that self-reported performance measures have less range restriction and less error than several purportedly objective measures.

The burnout dimensions are based on the work of Maslach and Jackson (1981). These scales were applied to the sales situation by Singh et al. (1994).

To study the mediating role of burnout in the role stress process we had to include the role stress scales. The role stress scales were adopted from Rizzo, House, and Lirtzman (1970). These scales were used because they have been frequently used in the sales management literature (Fine \& Shepherd, 1994).

To gauge emotional contagion scales were adopted from the literature of psychology. The emotional contagion scale was adopted from Doherty, Orimoto, Hebb, and Hatfield (1993) and the facial expressiveness scale was adopted from Klein and Cacioppo (1993). Both scales are presented in the Appendix. The scale dimensions, the amount of items, and the reliabilities are shown in Table 2.

\section{RESULTS}

Based upon the median of each scale the individuals were allocated their positions in our typology. The composition of these groups is as follows: charismatics $n=61$; empathetics $n=38$; expansives $n=30$; and the bland $n=64$. In fact these cell sizes reflect a positive correlation between the scales (correlation of 0.50).

An ANOVA design was used to test the first two hypotheses. First, for every hypothesis an ANOVA was performed in order to test if the groups differed from each other on that scale. Next a Duncan test was administered to test if the groups significantly differed from each other on each scale. 


\section{H1: Sales Performance}

As expected, the charismatics score highest on sales interactions and they are significantly better at it than the blands and expansives, who have equal scores (see Table 3). The empathetics score second, yet not significantly different from the charismatics, expansives, and blands. This part of the hypothesis is thus partially supported. The data on sales volume also provide partial support for the hypothesis. First, the charismatics and the emphatics reach higher sales volume than the expansives (who score lowest), but there was no significant difference between the charismatics and the empathetics (a difference which was anticipated). The blands scored lower than both the charismatics and empathetics, but not lower than the expansives. This last observation was not hypothesized. So this part of the hypothesis is partially substantiated. In regard to relationship capacity, the differences between the four configurational types were least explicit $(p=.06)$. The charismatics scored highest on relationships capacity and this was significantly different from the expansives (as was hypothesized), but this score was not significantly different from the empathetics and the blands. Although the empathetics scored second on relationship capacity, the score was not significantly different than that of the charismatics. The blands scored third, but their score was not significantly different from that of the charismatics and expansives (who had the lowest relationship performance score). In short, the data here show that $\mathrm{H} 1$ is partially substantiated; in fact, the charismatic and emphatic salespeople have a higher score on all three dimensions of sales performance.

\section{H2: Burnout}

As expected, and shown in Table 4, there are differences in two dimensions of burnout. Depersonalization and emotional exhaustion differ, whereas there are no differences between the groups on reduced personal accomplishment. As far as depersonalization is concerned, expansives, followed by the charismatics and the empathetics, do have a high degree of burnout. This part of H2 is thus partially substantiated. Concerning emotional exhaustion, this part

Table 3. The Relationships between Typology and Sales Performance

\begin{tabular}{llllllll}
\hline Variables & Charismatics & Empathetics & Expansives & Bland & $F$ & $p$ & Duncan \\
\hline $\begin{array}{l}\text { Sales } \\
\text { interaction }\end{array}$ & 5.4 & 5.2 & 5.0 & 5.0 & 3.8 & .01 & $\begin{array}{c}\mathrm{CH}>\mathrm{EX} \\
\& \mathrm{CH}>\mathrm{BL}\end{array}$ \\
Sales volume & 5.0 & 5.0 & 4.6 & 4.8 & 2.8 & .04 & $\begin{array}{c}\mathrm{CH}>\mathrm{EX} \\
\& \mathrm{EM}>\mathrm{EX}\end{array}$ \\
Relationships & 5.6 & 5.4 & 5.1 & 5.3 & 2.6 & .06 & \begin{tabular}{c}
$\mathrm{CH}>\mathrm{EX}$ \\
\hline
\end{tabular}
\end{tabular}


Table 4. The Relationships between Typology and Burnout

\begin{tabular}{llllllll}
\hline Variables & Charismatics & Empathetics & Expansives & Bland & $F$ & $p$ & Duncan \\
\hline $\begin{array}{l}\text { Depersonalization } \\
\begin{array}{l}\text { Emotional } \\
\quad 3.1\end{array}\end{array}$ & 3.0 & 3.3 & 2.7 & 4.1 & .00 & $\begin{array}{r}\mathrm{EX}>\mathrm{BL} \& \\
\mathrm{CH}>\mathrm{BL}\end{array}$ \\
$\begin{array}{l}\text { Reduced personal } \\
\text { accomplishment }\end{array}$ & 2.5 & 2.7 & 2.3 & 2.2 & 2.9 & .03 & $\begin{array}{r}\mathrm{EM}>\mathrm{BL} \& \\
\mathrm{EM}>\mathrm{CH}\end{array}$ \\
\hline
\end{tabular}

of $\mathrm{H} 2$ is also partially substantiated by the data: the empathetics and the charismatics have the highest score on burnout. But scores of the charismatics and emphatics do not differ significantly from each other. There are no differences among the groups on the personal accomplishment dimension, which was not expected. The data here show that $\mathrm{H} 2$ is partially substantiated, as the charismatics and empathetics are a group vulnerable to burnout (depersonalization and emotional exhaustion). Against expectations, the expansives are even more vulnerable to burnout.

\section{The Amplifying Role of Sensitivity to Emotions on the Mediating Role of Burnout in the Stress Process}

Next, the mediating burnout hypothesis as suggested b Singh et al. (1994) was tested with EQS (Bentler, 1992; Byrne, 1994). As shown in Table 5, in the resulting Model 1 not all the paths between role stress, burnout, and performance were significant, which is in accordance with Singh et al. (1994). However, the general pattern of the model (reflecting the mediating thesis of Singh et al., 1994) fit the data very well. ${ }^{4}$ The CFI is $0.98, p$ value $=.09, \chi^{2}=27.6$, and $d f=19$. Graphically the model is as shown in Figure 1. From this figure 1 it is apparent that whereas the groups in the ANOVA (see Table 4) did not differ in reduced personal accomplishment, reduced personal accomplishment has a major effect on performance in this structural stress process model. In other words, from a structural perspective it is the reduced personal accomplishment as a result of role stress that mostly affects the performance of the salesperson. Next, it will be investigated whether the mediating role of burnout is stable among the contagious groups.

In order to investigate whether the mediating hypothesis of Singh et al. (1994) is stable among the four groups, we ran a

\footnotetext{
${ }^{4}$ Before testing the model, it was checked, by computing the Cronbach alpha, whether the constructs in the two groups had similar factor loadings. The Cronbach alphas of most constructs across the two groups were quite stable. Subsequently, we proceeded with testing the model of Singh et al. (1994).
} 
Table 5. The Parameter Values of the Structural Model Analysis

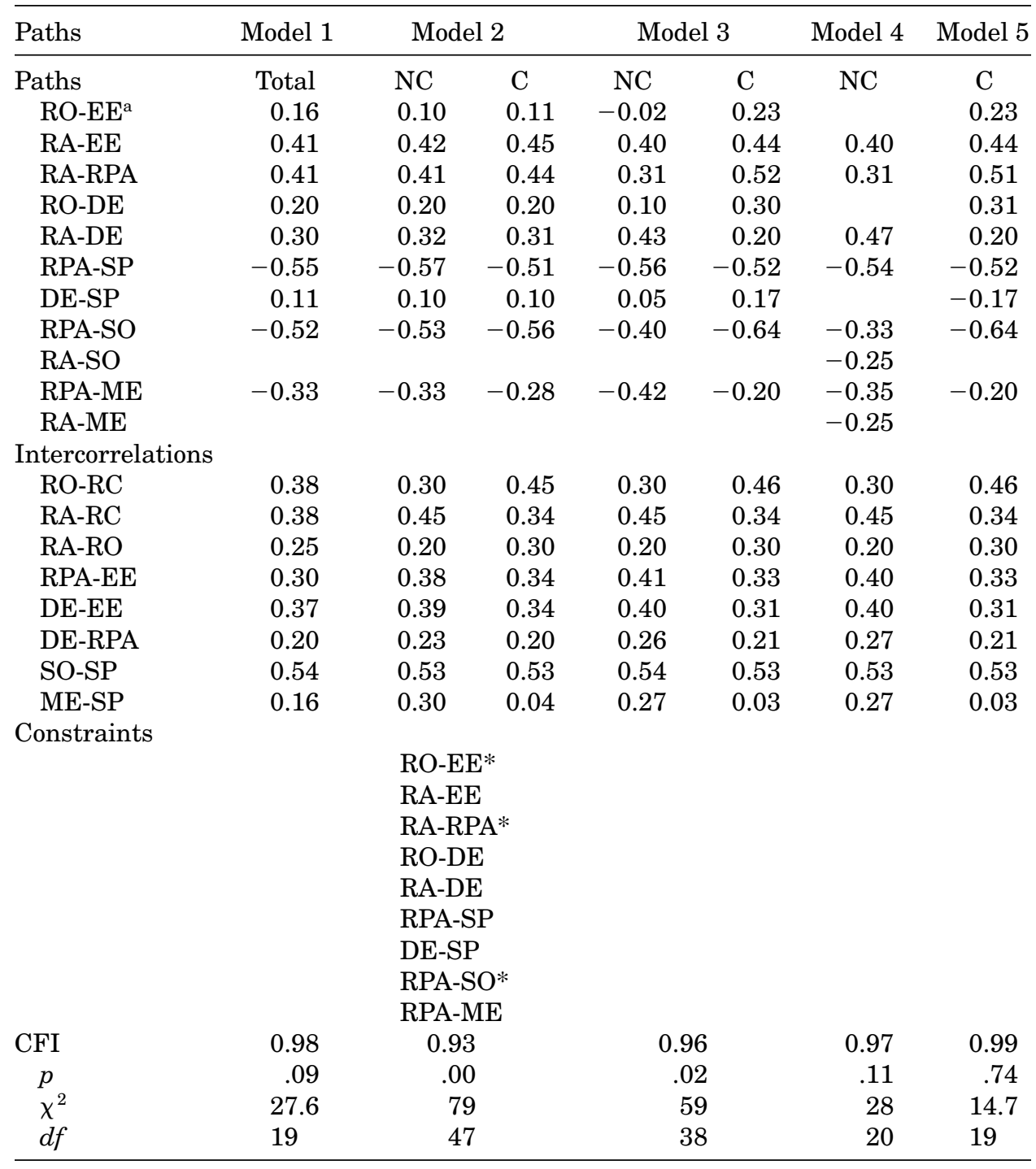

${ }^{\mathrm{a}} \mathrm{RC}=$ role conflict, $\mathrm{RO}=$ role overload, $\mathrm{RA}=$ role ambiguity, $\mathrm{EE}=$ emotional exhaustion, $\mathrm{RPA}=$ reduced personal accomplishment, $\mathrm{DE}=$ depersonalization, $\mathrm{SO}=$ sales volume, $\mathrm{ME}=$ relationship capacity, $\mathrm{SP}=$ sales presentations, $\mathrm{CFI}=$ Comparative Fit Index, $\mathrm{P}=p$ value, $\chi^{2}=$ chi square, $d f=$ degrees of freedom.

simultaneous four-group analysis within EQS (Byrne, 1994). The sample size for each group (especially the empathetics and the expansives), however, is too small in order to run a complete fourgroup comparison analysis. Therefore, we have grouped the charismatics and empathetics together in which we called the contagious group, and the bland and expansives in a combined noncontagious group with respect to the mediating hypothesis. In what follows we therefore will only discuss the way in which contagious 


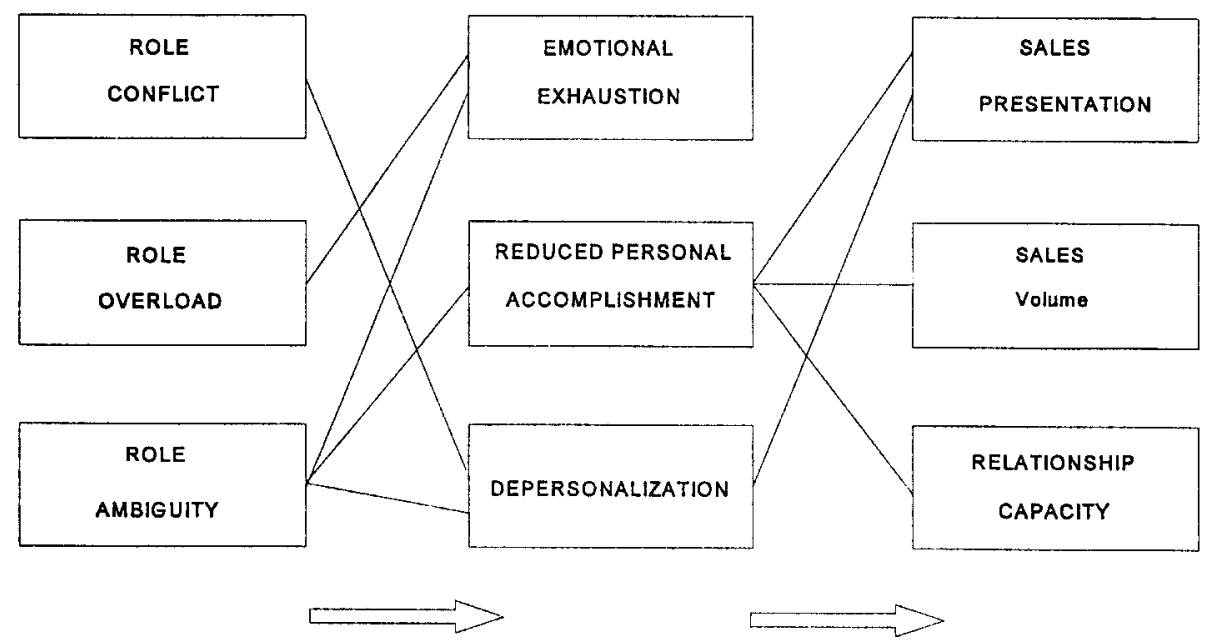

Figure 1 The path model reflecting the mediating role of burnout between role stress and performance.

versus noncontagious groups differ from each other. The following steps were undertaken:

1. First, as mentioned earlier, the mediating model was estimated by using the total population. The paths of the model are shown in Table 5 (column 1).

2. Second, in order to test if the mediating model was invariant across the contagious group (labeled $\mathrm{C}$ ) and the noncontagious group (labeled NC), a constrained model of the first model (Model 2) was used. In addition, the mediating model was tested in an unconstrained fashion (Model 3). Subsequently, the chi-square and $d f$ differences were computed, and by using chi-square tables it was determined whether models (2) and (3) differed from each other. From the following observations we may conclude that Model 1 does not fit both groups:

(a) The CFI and $p$ values of the two groups model became lower.

(b) The average standardized residuals, especially for the NC groups, are substantial (0.10).

(c) The chi-square table shows that the chi-square differences and the $d f$ difference are under 0.05 , which implies that both populations differ substantially.

(d) Three constraints were significantly different (they are marked with an asterisks). 
3. Subsequently, both groups were estimated separately. Model 4 reflects the estimation of the noncontagious group, and Model 5 estimates the contagious group. There are far more paths between role stress and burnout in the contagious group (C), and the remaining paths in both groups are stronger in the contagious groups than in the noncontagious group (NC). Also, there are more paths heading from burnout to performance. In other words, the mediating hypothesis as suggested by Singh et al. (1994) is not stable between groups, which substantiates H3.

\section{DISCUSSION}

The goal of this article was to present the emotional contagion hypothesis within a sales context. Emotional contagion is an important topic for salespeople, as it is intuitively apparent that emotions affect the dynamics of the interaction between a salesperson and his role members (especially the customers). Scientifically, the influence of emotions is more elusive, partly because there has not been much research done on human emotions in the sales area. This article especially investigated the long term consequences of salespeople transmitting their emotions onto others, or being infected by other people's emotions.

In general, the data display patterns in accordance with the hypotheses: the charismatics and the empathetics - those who are able to transmit emotions or pick up emotions - are better performers. It makes sense, therefore, to consider the ability to control and empathize with customers (and other role members) an asset. Empathy, which is characteristic for the catchers (indicative for the charismatics and empathetics), is, however, a liability, as there are greater risks for burnout. There was another twist in the data: It became apparent that the most vulnerable group were the expansives (high ability to infect, but no ability to become infected by emotions). They were the poorest performers and had high levels of burnout. At last, there was substantiation for the amplifying role of emotional sensitivity on the mediating role of burnout in the stress process.

\section{Managerial Implications}

Managers always look for people with high sales potential, especially emotionally intelligent people. This study shows that further investigation of emotional dimensions may offer valuable guidance for hiring such people. However, the data show something more important as well: Generally emotionally sensitive salespersons are more vulnerable to burnout. Perhaps the contagious salespersons (the catchers) need closer monitoring by the managers. This adds a twist to what sales experts say: Knowing who someone is is not as essential as 
knowing what the company does with that person. This study, however, suggests that it makes a great deal of sense to get to know a person's physiological constitution, because this allows managers to deal with these people in a better way.

\section{CONCLUSION}

In this article it is proposed that emotions affect the salesperson's interactions with role members (especially customers). Based upon the emotional contagion hypothesis, four personality types were constructed, and these personality types were found to show certain consistencies. Being sensitive to the emotions of others (which characterizes empathetics), as well as being able to control this in combination with emotional sensitivity (which characterizes charismatics) are assets for communication, and consequently result in better performance. However, being sensitive to emotions of the others is a liability as well, because chances of burnout become more likely. Management must take emotional contagiousness seriously and consider its assets and liabilities.

\section{APPENDIX}

\section{The Emotional Contagion Scale} (Anchors 1 = Never; 7 = Always)

1. It doesn't both me to be around angry people.

2. I find myself nodding off when I talk with someone who is depressed.

3. I feel tender and gentle when I see a mother and child hugging each other affectionately.

4. Being around depressed people makes me feel depressed.

5. I pay attention to what other people are feeling.

6. I feel alive and vibrant when I am with the one I love.

7. When someone laughs hard, I laugh too.

8. When people hug me affectionately, I get upset and I want to back away.

9. I'm very accurate in judging other people's feelings.

10. When I am around people who are angry, I feel angry myself.

11. I find myself clenching my fist when overhearing others quarrel.

12. I wince while observing someone flinching while getting a shot.

13. I'm very sensitive in picking up other people's feelings.

14. I keep a straight face when those around me are laughing hard. 
15. Listening to the shrill screams of a terrified child in a dentist's waiting room makes me feel nervous.

16. Even if someone I'm talking with begins to cry, I don't get teary eyed.

17. When someone paces back and forth, I feel nervous and anxious.

18. When someone smiles warmly at me, I smile back and feel happy inside.

\section{The Facial Expressiveness Scale (Anchors $1=$ Never; 7 = Always)}

1. I can't help but let other people know when I'm glad to see them.

2. People can tell I have a problem from my expression.

3. I tend to touch friends during conversation.

4. I laugh a lot.

5. People have told me that I am an expressive person.

6. I show that I like someone by hugging or touching that person.

7. I get excited easily.

8. People can tell from my facial expression how I am feeling.

9. When I am alone I can make myself laugh by remembering something from the past.

10. Watching television or reading a book can make me laugh out loud.

\section{REFERENCES}

Baron, R., \& Kenny, D. (1986). The moderator-mediator variable distinction in social psychological research: Conceptual, strategic, and statistical consideration. Journal of Personality and Social Psychology, 51, 1173-1182.

Behrman, D. N., \& Perreault, W. D. (1982). Measuring the performance of industrial salespersons. Journal of Business Research, 10, 355-370.

Bentler, P. (1992). EQS: Structural equation program manual. Los Angeles: BMDP Statistical Software.

Bitner, M. J. (1992). Servicescapes: The impact of physical surroundings on customers and employees. Journal of marketing, 57-71.

Byrne, B. M. (1994). Structural equation modeling with EQS and EQS windows: Basic concepts, applications, and programming. Newbury Park: Sage.

Churchill, G., Jr., Ford, N., Hartley, S., \& Walker, O., Jr. (1985). The determinants of salesperson performance: A meta analysis. Journal of Marketing Research, 22, 103-118.

Cordes, C., \& Dougherty, T. (1993). A review and integration of research on job burnout. Academy of Management Review, 18, 621-656.

Damasio, A. (1994). Descarte's error: Emotion, reason and the human brain. New York: Putnam's. 
Doherty, R. W., Orimoto, L., Hebb, J., \& Hatfield, E. (1993). Emotional contagion: Gender and occupational differences. Unpublished manuscript, University of Hawaii, Honolulu.

Dorsey, D. (1994). The force. New York: Ballantine.

Dun \& Bradstreet. (1994). Dun's 25,000. Amsterdam: Dun \& Bradstreet International BU.

Fine, L., \& Shepherd, C. (1994). Scaling and measurement: Role conflict and role ambiguity reconsidered. Journal of Personal Selling and Sales Management, $57-65$.

Goleman, D. (1995). Emotional intelligence. New York: Bantam.

Greenwald, A. G., \& Banaji, M. R. (1995). Implicit social cognition: Attitudes, self esteem, and stereotypes. Psychological Review, 102, 4-27.

Hatfield, E., Cacioppo, J. T., \& Rapson, R. L. (1994). Emotional contagion. New York: Cambridge University Press.

Heneman, G. (1974). Comparisons of self and superior ratings of managerial performance. Journal of Applied Psychology, 59, 638-642.

Hornik, J. (1992). Tactile stimulation and consumer response. Journal of Consumer Research, 19, 449-458.

Isen, A., \& Means, B. (1983). The influence of positive affect on decisionmaking strategy. Social Cognition, 2, 18-31.

Kahneman, D., \& Tversky, A. (1985). Prospect theory: An analysis of decision under risk. Econometrica, 47, 263-291.

Klein, D., \& Cacioppo, J. L. (1993). The facial expressiveness scale and the autonomic reactivity scale. Unpublished manuscript, Ohio State University, Columbus.

Lee, R., \& Ashfort, B. (1996). A meta-analytic examination of the correlates of the three dimensions of job burnout. Journal of Applied Psychology, 81, $123-133$.

Leigh, T., \& Rhetans, A. (1984). A Script-theoretic analysis of industrial purchase behavior. Journal of Marketing, 48, 22-32.

Maslach C., \& Jackson, S. E. (1981). The measurement of experienced burnout. Journal of Occupational Behavior, 2, 99-113.

McBane, D. A. (1995). Empathy and the salesperson: A multidimensional perspective. Psychology and Marketing, 12, 394-369.

Olshavsky, R. (1973). Customer-salesmen interactions in appliance retailing. Journal of Marketing Research, 10, 208-212.

Rizzo, J. R., House, R. J., \& Lirtzman, S. I. (1970). Role conflict and ambiguity in complex organizations. Administrative Science Quarterly, 15, 150-163.

Saxe, R., \& Weitz, B. A. (1986). The SOCO scale: A measure of the customer orientation of salespeople. Journal of Marketing Research, 23, 343-351.

Schacter, D. L., \& Tulving, E. (1994). Memory systems. Cambridge, MA: Bradford.

Schuster, C., \& Danes, J. (1986). Asking questions: Some characteristics of successful sales encounters. Journal of Personal Selling and Sales Management, $17-27$.

Singh, J., Goolsby, J. R., \& Rhoads, G. K. (1994). Behavioral and psychological consequences of boundary spanning burnout for customer service representatives. Journal of Marketing Research, 33, 558-569.

Soldow, G., \& Thomas, G. (1984). Relational communication: Form versus content in the sales interaction. Journal of Marketing, 48, 84-93. 
Sperber D., \& Wilson, D. (1987). Precis of relevance: Communication and cognition. Behavioral and Brain Sciences, 10, 697-754.

Spiro, R. L., \& Weitz, B. A. (1990). Adaptive selling: conceptualization, measurement and nomological validity. Journal of Marketing Research, 29, 61-69.

Swenson, M., Singh, J., \& Rhoads, G. K. (1994). Relationship performance. Working paper, Brigham young University, Provo, UT.

Szymansky, D., \& Churchill, G., Jr. (1990). Client evaluation cues: A comparison of successful salespeople. Journal of Marketing Research, 27, 163-174.

Tassinary, L. G., Cacioppo, J. T., \& Geen, T. R. (1989). A psychometric study of surface electrode placements for facial electromyographic recording: I. The brow and cheek muscle regions. Psychophysiology, 26, 1-16.

Weitz, B. A. (1981). Effectiveness in sales interactions: A contingency framework. Journal of Marketing, 45, 85-103.

Weitz, B. A., Castleberry, S. B., \& Tanner, J. F. (1992). Selling: Building partnerships. Homewood, IL: Irwin.

Weitz, B. A., Sujan, H., \& Sujan, M. (1986). Knowledge, motivation, and adaptive behavior: A framework for improved selling effectiveness. Journal of Marketing, 50, 174-191.

Willet, R., \& Pennington, A. (1966). Customer and salesman: The anatomy of choice and influence in a retailing setting. In R. Hass (Ed.), Technology and marketing (pp. 598-616). Chicago: AMA.

Zajonc, R. B. (1965). Social facilitation theory. Science, 149, 269-274.

The author of this article is grateful to the research group on socioneuroscience at the Ohio State University, especially John Cacioppo and David Klein, for useful comments; to the professors at Case Western Reserve University, especially Professor J. Singh; and to the participants of the Fifth Workshop on Quality Management on Services, EIASM, Tilburg, The Netherlands.

Correspondence concerning this article should be sent to: Willem Verbeke, ISAM, H 19-17, School of Economics, Erasmus University, P.O. Box 1738, 3000 DR Rotterdam, The Netherlands (roverw@wirehub.nl). 